\title{
Internal audit public sector capability: a case study
}

\author{
Jacobus Oosthuizen Janse van Rensburg ${ }^{1}$ and Philna Coetzee ${ }^{2 *}$ \\ ${ }^{1}$ Department of Auditing, University of Pretoria, Pretoria, Gauteng, South Africa \\ ${ }^{2}$ Department of Auditing, Tshwane University of Technology, Pretoria, Gauteng, South Africa
}

\begin{abstract}
Internal auditing is an essential part of governance and can be a valuable asset to public sector institutions. However, for public sector internal auditing to effectively support management, the internal audit function (IAF) should be capable. The question arises as to how the capability of public sector IAFs can be measured. The Institute of Internal Auditors Research Foundation published the Internal Audit Capability Model (IA-CM) in 2009 to provide a capability self-assessment tool for public sector IAFs. The main objective of the study is to determine whether the IA-CM can be used successfully to measure internal audit capability levels, and a secondary objective is to determine whether the tool can be successfully adapted for a specific public sector organisation and/or country. To achieve these objectives, the model was applied in a South African public sector organisation by means of a case study, where the IAF of the case was ranked against the key process areas (KPAs) of the model. The ranking was conducted based on a documentary review and interviews with applicable officials within the case. The model was successfully tested in measuring the internal audit capability level of a South African public sector organisation; however, a total of eight potential feasibility hindrances or considerations have been identified that could negatively affect the implementation of seven of the KPAs of the IA-CM.
\end{abstract}

\section{INTRODUCTION}

No nation can function in an orderly manner without an effective government. The citizens of a country cannot fulfil all their needs in an individual capacity and are dependent on their government for many basic infrastructural needs. There are many critical success factors that should be in place for a government to be effective, two of which are sound public administration policies and governance structures. The core components of sound governance relate to good leadership, stakeholder engagement, sustainability and citizenship (OECD, 2004; IOD, 2009; ASX, 2010: 10-12; FRC, 2010: 6-7). An essential contributor to sound governance is internal auditing (OECD, 2004: 62; IOD, 2009: 93; ASX, 2010: 34). In its role as independent evaluator

*Correspondence to: Jacobus Janse van Rensburg, Department of Auditing, University of Pretoria, Pretoria, Gauteng, South Africa. E-mail: cobus.jansevanrensburg@up.ac.za in terms of the assurance and consulting services that it provides, internal auditing should be an integral part of any organisation's governance structure (IIA, 2012; IOD, 2009: 17, 93), not only in the private sector, but also the public sector (Subramaniam, $\mathrm{Ng}$ \& Carey, 2004: 87; Khoury, 2011: 45).

For internal auditors to perform their role effectively within the public sector governance arena, they have to be sufficiently capable in terms of their mandate and objectives (Van Gansberghe, 2005: 70; Mihret \& Yismaw, 2007: 472; Asare, 2009: 22-23; IIARF, 2009: 1; Aikins, 2011: 333). Capability is defined as the measurement of the ability of a department organisation, person or system to achieve objectives related to its mission (Mihret \& Yismaw, 2007: 471; Businessdictionary.com, 2015). As the main mission of internal auditing is to assist management in achieving its objectives and to add value by independently evaluating the adequacy and effectiveness of governance, risk management and control processes (IIA, 2011: 2), the capability of internal 
audit functions (IAFs) should be in line with the mandate of the organisations they serve. Internal auditors in the private sector should be fully able to assist their organisations in fulfilling their main mandates, namely profit-making and increasing shareholder value. Likewise, internal auditors in the public sector should be able to assist their organisations in achieving their objectives, namely to provide services to the public by assisting their organisations in mitigating the risks that are unique to the public sector; ultimately resulting in improvement of the performance of the public sector and increased citizens confidence.

The question arises as to how this capability of public sector IAFs can be determined. The global professional body of the internal audit profession, the Institute of Internal Auditors (IIA), published the Internal Audit Capability Model (IA-CM) in 2009 to provide a capability self-assessment tool for public sector IAFs. Being developed on best practice principles, the IA-CM is a comprehensive capability model that might assist in answering the aforementioned question. As the IA-CM was developed for a global body and was not tested by the IIA, the question arises as to whether the model can be used to measure the capability of IAFs successfully, especially within a specific country or organisation. Therefore, the main objective of the study reported in this article is to determine whether the IA-CM can be used successfully to measure internal audit capability levels, and a secondary objective is to determine whether the tool can be successfully adapted for a specific public sector organisation and/or country. To achieve these objectives, the model was applied in a South African public sector organisation by means of a case study.

The Institute of Internal Auditors Research Foundation (IIARF) has been identified as the main stakeholder that could benefit from this study as they are the developers of the model that was used as the basis of this study. The results could be used to improve or refine the model and to highlight potential feasibility hindrances with regard to the implementation of the model. The selected case, namely the national department that was selected as the sample unit of this study, has been identified as a secondary stakeholder, as the study reveals several specific recommendations with regard to enhancing the capability of the IAF. The overseer of internal auditing within the South African public sector is also a stakeholder and could benefit from the results of this study. Other IIAs as well as IAFs worldwide could also use the outcome of this study to understand the problem areas and thus refine the IA-CM for use in their specific country or organisation.
The article is set out as follows: background information on internal auditing in the public sector and the development of the IA-CM are discussed, whereafter the research method used, results of the research conducted and the conclusions and recommendations are presented.

\section{BACKGROUND INFORMATION}

\section{Internal auditing in the public sector}

Changes have been evident in the public sector over the last few years (Van Schendelen, 2012: 40-42), with an increased focus on the accountability, effectiveness and efficiency of its services (Van Gansberghe, 2005: 70). Citizens are demanding more transparency and better services, while resources are growing at a slower pace. This presents a unique set of risks for the public sector. The importance of internal auditing in the public sector is highlighted by this increased focus on and need for accountability (Asare, 2009: 23; Aikins, 2011: 307-309; World Bank, 2011). As public sector organisations do not have the same built-in performance and accountability measures as the private sector (Jarrar \& Schiuma, 2007: 4-5) additional accountability structures, such as IAFs, can add significant value. However, as mentioned before, to address this need, public sector IAFs should be sufficiently capable in order to provide the required level of assistance. Capability is a prerequisite for the achievement of any objective. Without the ability to perform a function, it cannot be executed effectively. It follows that the continuous measurement of capability is essential for determining the extent to which a specific function, such as internal auditing, is able to achieve its mandate.

To understand what capability entails for internal auditing within the public sector, the evolution of the profession must be understood as well as the current challenges faced by this sector and the role of internal auditing. Traditionally, public sector internal audit efforts were mainly directed at the review of financial controls (financial audits). Subsequently, internal audit focus shifted to all organisational processes, initially, from a compliance audit point of view. However, during the last two decades, attention has shifted to the evaluation of the economic, efficient and effective allocation and utilisation of public resources (Coupland, 1993: 4; Goodwin, 2004: 641; Van Gansberghe, 2005: 69-70; Sterck \& Bouckaert, 2006: 49; Khoury, 2011: 42). In addition, aspects such as public sector performance, budgeting, accrual accounting and the accountability of reported results have come to the fore (Sterck 
\& Bouckaert, 2006: 49; Khoury, 2011: 41). The reason for this re-emphasis can be ascribed to the limited resources within the public sector and the restrictions in the allocation of such resources (Coupland, 1993: 4; Aikins, 2011: 306). The importance of internal auditing in the public sector is further highlighted by the various public sector-specific guidance documents and forums developed by the IIA, such as the supplemental guidance on the role of auditing in public sector governance and the IA-CM (IIARF, 2009; IIA, 2012; IIA-SA, 2013).

The public sector of any country is faced with the challenge of meeting continuously increasing service delivery demands with limited resources (Curristine, 2005: 127). Apart from global challenges, countryspecific challenges for South Africa are included, as this model is tested within a South African context: a country with a unique history, a distinctive cultural population blend and a prominent internal audit profession. Studies (Curristine, 2005; Dorasamy, 2010: 57, 59; Aikins, 2011; Schepers, 2012: 334; Kellis \& Ran, 2012) and other documents (PSC, 2010; PSC, 2011; AGSA, 2013: 22-25; Ferguson, Ronayne, \& Rybacki, 2014) highlight the following challenges: service delivery challenges (historical inequities, slow public services/lack of commitment by public officials, inadequate response to citizen needs, inadequate coordination amongst the three spheres of government and unsatisfactory performance information), economic challenges (unemployment and lack of job creation, fraud, corruption and unethical leadership, ineffective and inefficient utilisation of state resources and insufficient resources), human resource challenges (skill shortages, inadequate human resource performance and plans, ineffective public sector accountability systems and gender and disability human resource representation targets not achieved) and compliance challenges (high percentage of qualified/adverse external audit opinions and non-compliance with legislation and guidelines).

In light of these challenges, internal auditing can add value by assisting management to minimise risks associated with each challenge. For example, with regard to the economic challenge relating to fraud, corruption and unethical leadership, IAFs can add value by ensuring that this risk is sufficiently evaluated in terms of the likelihood of occurring and provide assurance on the prevention processes (IIA, 2011: 20-21). It can also be argued that public sector employees will most probably be more careful with public resources and more reluctant to commit fraud when an effective and capable IAF evaluates their actions on a continuous basis (Mafunisa, 2007: 260; Asare, 2009: 23; Burnaby, Howe \& Muehlmann, 2011: 195, 222). Public sector
IAF can therefore make a valuable contribution in assisting the public sector in addressing their challenges. Internal auditing can, however, only make this contribution if the auditors are suitably qualified, competent and capable to do so. The question can be raised as to when it can be said that an IAF within the public sector is suitably capable of effectively assisting their organisations.

\section{Internal audit capability model}

The IA-CM, as a tool for measuring public sector internal audit capability, is briefly discussed in this section. The need for a capability model was first expressed by the Public Sector Committee of the IIA Global in 2004 (IIARF, 2009: 1) in order to strengthen the important role that internal auditing plays towards public sector accountability and governance. Being a global body, the lack of a universal model that can be applied within any country's public sector was a further concern. The IA-CM was published in 2009 by the IIARF. The main purpose of the model is to provide a capability selfassessment and continuous improvement tool for public sector IAFs. The model was based on the capability maturity model and the capability maturity model integration of the Software Engineering Institute (IIARF, 2009: 1). These models have been used as the foundation of many modern capability models (Hillson, 1997: 36; Chapman, 2009; Becker, Niehaves \& Simons, 2010: 10; Janse van Rensburg \& Coetzee, 2011: 50).

The use of capability or maturity models has come to the fore over the last decade and is recognised worldwide (Persse, 2001; De Bruin, Freeze, Kaulkarni \& Roseman, 2005; Becker et al., 2010: 2), receiving significant research attention. It can be defined as a multi-level evolutionary path that outlines the aspects required for maturity with regard to a specific process or activity (De Bruin et al., 2005; Becker et al., 2010: 2), including capability, competency and level of sophistication.

The IA-CM, consistent with the capability maturity model and capability maturity model integration structure, consist of five capability levels, six essential elements of internal auditing and 41 key process areas (KPAs), linking the various capability levels and elements, indicating how the relevant IAF can move from one capability level to the next. The five levels commence with level one (initial) indicating that the IAF is unstructured; level two (infrastructure) indicating that a certain level of repeatability and sustainability is in place with regard to the practices of the IAF; level three (integrated) 
indicating that the management, policies and processes of the IAF are integrated with the organisational policies; level four (managed) indicating that the IAF's expectations are aligned with the expectations of key stakeholders; and level five (optimising) suggesting that the IAF is continuously learning and improving (IIARF, 2009: 7-9). The six elements consist of the 'services and role' referring to the nature and scope of the services that the IAF provides; 'people management' focusing on the extent to which internal audit human resources are acquired and developed; 'professional practices' reflecting the processes, frameworks and policies required; 'performance management and accountability' referring to the required information that enables the IAF to operate effectively; 'organisational relationships and culture' referring to the internal and external position of and relationships with the IAF; and 'governance structures' constituting the functional and administrative reporting structures of the head of the IAF, commonly referred to as the chief audit executive (CAE), as well as the organisational position of the IAF within the organisation (IIARF, 2009: 11-12, 14). The model was developed in such a way that the KPAs within each capability level provide the building blocks to move from one capability level to the next. Capability levels can therefore not be passed over (IIARF, 2009: 54).

A comprehensive search on the use or application of the IA-CM revealed that the model was applied in the United Kingdom Ministry of Defence (Macrae, 2010), resulting in positive and developmental findings for the IAF. However, the methodology used, shortcomings, adaption and pitfalls of the application of the model were not documented. This leaves the questions of whether the model was successful in measuring internal audit capability and whether the model can be used in any country or organisation unanswered.

\section{RESEARCH METHOD}

As the objective of the study involves the application of an already existing model (IA-CM), a single case study research design was selected (Yin, 2009: 47-48). A South African national department was chosen, the reason being that the IAFs in this sphere of government appear to be more effective (AGSA, 2011: 33, 40) and thus having a better chance of being mature and applicable to the IA-CM. The population consisted of the 40 South African national departments as on 6 May 2014. Three assessment reports, namely the Presidency's Management
Performance Assessment Tool scorecard of national departments self-assessment (Presidency, 2011), the Management Performance Assessment Tool formal assessment report (Presidency, 2013) and the 2011/2012 consolidated Auditor-General's report on national and provincial audit outcomes (AGSA, 2012), were used to determine the maturity of the national department's IAFs. All three reports used a four-scale assessment criteria framework, where level 1 constitutes the lowest scoring and level 4 the highest. Nine departments obtained a score between 3.7 and 4 with one being selected as the sample unit of this study based on professional judgement and accessibility to the final target population. For confidentiality purposes, the name of the selected department is not disclosed.

The process followed to test the IA-CM was as follows: Information was gathered through a documentary review and semi-structured interviews with applicable role players within the selected case. A checklist was prepared to gather the information. The checklist consists of 184 questions that had to be answered based on the IA-CM KPAs. Some of these were answered by means of a documentary review. The remaining questions were answered by means of interviews conducted with the CAE-136 questions; the audit committee chairperson (ACC) -109 questions; the chief operating officer (COO) - 84 questions; and a senior internal auditor-68 questions. Answers were captured as 'Yes', 'No' or 'Partially'. Additional questions were posed to the interviewees, especially when a 'No' or 'Partially' answer was provided in order to determine the reasons why a specific KPA was not implemented and to identify potential feasibility hindrances to the effective application. These were documented as 'considerations' in Tables 1-6, as per the stakeholder that is affected.

\section{RESEARCH RESULTS}

In this section, the research findings are presented; the information gathered during the case study and the considerations identified are presented for each of the six IA-CM elements. Thereafter, the selected case's IAF is ranked based on the IA-CM.

\section{Services and role of internal auditing}

The extent to which each of the five KPAs of the IA$\mathrm{CM}$ on the services provided and the role of IAFs can be effectively applied is summarised in Table 1. 
Table 1 Services and role of internal auditing

\begin{tabular}{|c|c|c|c|c|c|c|c|c|c|}
\hline \multirow[b]{2}{*}{ Level } & \multirow[b]{2}{*}{ KPA } & \multirow{2}{*}{$\begin{array}{l}\text { Number } \\
\text { of } \\
\text { questions }\end{array}$} & \multicolumn{2}{|c|}{$\begin{array}{c}\text { Documentary } \\
\text { review }\end{array}$} & \multicolumn{3}{|c|}{ Interviews } & \multicolumn{2}{|c|}{ Considerations } \\
\hline & & & Yes & No & Yes & No & Partially & IIARF & Case \\
\hline 2 & Compliance auditing & 5 & 5 & & & & & & \\
\hline 3 & $\begin{array}{l}\text { Performance } \\
\text { auditing }\end{array}$ & 5 & 5 & & & & & & \\
\hline 3 & Advisory services & 7 & 2 & 2 & & 3 & & & 5 \\
\hline 4 & GRC & 5 & 1 & & & 3 & 1 & & 4 \\
\hline 5 & Key agent of change & 9 & & & 2 & 5 & 2 & 2 & 5 \\
\hline Total & & 31 & 13 & 2 & 2 & 11 & 3 & 2 & 14 \\
\hline
\end{tabular}

KPA, key process area; IIARF, Institute of Internal Auditors Research Foundation; GRC, governance, risk management and control.

Table 2 People management

\begin{tabular}{|c|c|c|c|c|c|c|c|c|c|}
\hline \multirow[b]{2}{*}{ Level } & \multirow[b]{2}{*}{ KPA } & \multirow{2}{*}{$\begin{array}{l}\text { Number } \\
\text { of } \\
\text { questions }\end{array}$} & \multicolumn{2}{|c|}{$\begin{array}{l}\text { Documentary } \\
\text { review }\end{array}$} & \multicolumn{3}{|c|}{ Interviews } & \multicolumn{2}{|c|}{ Considerations } \\
\hline & & & Yes & No & Yes & No & Partially & IIARF & Case \\
\hline 2 & Skilled people recruited and retained & 7 & 3 & & 2 & 1 & 1 & 1 & 1 \\
\hline 2 & Individual professional development & 6 & 6 & & & & & & \\
\hline 3 & Workforce coordination & 2 & & & 2 & & & & \\
\hline 3 & Professionally qualified staff & 6 & 2 & & 1 & 2 & 1 & 1 & 2 \\
\hline 3 & Team building and competency & 4 & 1 & & 1 & 2 & & & 2 \\
\hline 4 & Workforce planning & 4 & & & 4 & & & & \\
\hline 4 & IAF supports professional bodies & 2 & & & & 2 & & & 2 \\
\hline 4 & $\begin{array}{l}\text { IAF contributes to management } \\
\text { development }\end{array}$ & 2 & & & 1 & 1 & & 1 & \\
\hline 5 & Workforce projection & 3 & & & & 2 & 1 & & 3 \\
\hline 5 & $\begin{array}{l}\text { Leadership involvement with } \\
\text { professional bodies }\end{array}$ & 2 & & & & 2 & & 1 & 1 \\
\hline Total & & 38 & 12 & 0 & 11 & 12 & 3 & 4 & 11 \\
\hline
\end{tabular}

KPA, key process area; IIARF, Institute of Internal Auditors Research Foundation; IAF, internal audit function.

Table 3 Professional practices

\begin{tabular}{|c|c|c|c|c|c|c|c|c|c|}
\hline \multirow[b]{2}{*}{ Level } & \multirow[b]{2}{*}{ KPA } & \multirow{2}{*}{$\begin{array}{l}\text { Number } \\
\text { of } \\
\text { questions }\end{array}$} & \multicolumn{2}{|c|}{$\begin{array}{l}\text { Documentary } \\
\text { review }\end{array}$} & \multicolumn{3}{|c|}{ Interviews } & \multicolumn{2}{|c|}{ Considerations } \\
\hline & & & Yes & No & Yes & No & Partially & IIARF & Case \\
\hline 2 & Audit plan based on management priorities & 9 & 6 & & & 3 & & & 3 \\
\hline 2 & Professional practices and processes framework & 4 & & & & 4 & & & 4 \\
\hline 3 & Risk-based audit plans & 2 & 2 & & & & & & \\
\hline 3 & Quality management framework & 6 & 2 & & 3 & 1 & & & 1 \\
\hline 4 & $\begin{array}{l}\text { Audit strategy leverages organisation's } \\
\text { management of risk }\end{array}$ & 4 & 1 & & 3 & & & & \\
\hline 5 & Strategic IA planning & 3 & & & & 3 & & & 3 \\
\hline 5 & $\begin{array}{l}\text { Continuous improvement of professional } \\
\text { practices }\end{array}$ & 2 & & & & 1 & 1 & & 2 \\
\hline Total & & 30 & 11 & 0 & 6 & 12 & 1 & 0 & 13 \\
\hline
\end{tabular}

KPA, key process area; IIARF, Institute of Internal Auditors Research Foundation; IA, internal audit. 
Table 4 Performance management and accountability

\begin{tabular}{|c|c|c|c|c|c|c|c|c|c|}
\hline \multirow[b]{2}{*}{ Level } & \multirow[b]{2}{*}{ KPA } & \multirow{2}{*}{$\begin{array}{l}\text { Number } \\
\text { of } \\
\text { questions }\end{array}$} & \multicolumn{2}{|c|}{$\begin{array}{l}\text { Documentary } \\
\text { review }\end{array}$} & \multicolumn{3}{|c|}{ Interviews } & \multicolumn{2}{|c|}{ Considerations } \\
\hline & & & Yes & No & Yes & No & Partially & IIARF & Case \\
\hline 2 & IA business plan & 7 & 5 & & & 2 & & & 2 \\
\hline 2 & IA operating budget & 4 & 1 & & 3 & & & & \\
\hline 3 & IA management reports & 3 & & & 2 & 1 & & & 1 \\
\hline 3 & Cost information & 4 & & & 3 & 1 & & & 1 \\
\hline 3 & Performance measures & 3 & 3 & & & & & & \\
\hline 4 & $\begin{array}{l}\text { Integration of qualitative and quantitative } \\
\text { measures }\end{array}$ & 9 & 2 & & 1 & 5 & 1 & & 6 \\
\hline 5 & Public reporting on IA effectiveness & 4 & 1 & & 1 & 2 & & & 2 \\
\hline Total & & 34 & 12 & 0 & 10 & 11 & 1 & 0 & 12 \\
\hline
\end{tabular}

KPA, key process area; IIARF, Institute of Internal Auditors Research Foundation; IA, internal audit.

Table 5 Organisational relationships and culture

\begin{tabular}{|c|c|c|c|c|c|c|c|c|c|}
\hline \multirow[b]{2}{*}{ Level } & \multirow[b]{2}{*}{ KPA } & \multirow{2}{*}{$\begin{array}{l}\text { Number } \\
\text { of } \\
\text { questions }\end{array}$} & \multicolumn{2}{|c|}{$\begin{array}{l}\text { Documentary } \\
\text { review }\end{array}$} & \multicolumn{3}{|c|}{ Interviews } & \multicolumn{2}{|c|}{ Considerations } \\
\hline & & & Yes & No & Yes & No & Partially & IIARF & Case \\
\hline 2 & Managing within the IAF & 3 & & & 1 & & 2 & & 2 \\
\hline 3 & Integral component of management team & 4 & & & 4 & & & & \\
\hline 3 & Coordination with other review groups & 3 & & & 1 & & 2 & 1 & 1 \\
\hline 4 & CAE advises top-level management & 6 & 1 & & 3 & 2 & & & 2 \\
\hline 5 & Effective and ongoing relationships & 6 & & & 6 & & & & \\
\hline Total & & 22 & 1 & 0 & 15 & 2 & 4 & 1 & 5 \\
\hline
\end{tabular}

KPA, key process area; IIARF, Institute of Internal Auditors Research Foundation; IAF, internal audit function; CAE, chief audit executive.

Table 6 Governance structures

\begin{tabular}{|c|c|c|c|c|c|c|c|c|c|}
\hline \multirow[b]{2}{*}{ Level } & \multirow[b]{2}{*}{ KPA } & \multirow{2}{*}{$\begin{array}{l}\text { Number } \\
\text { of } \\
\text { questions }\end{array}$} & \multicolumn{2}{|c|}{$\begin{array}{l}\text { Documentary } \\
\text { review }\end{array}$} & \multicolumn{3}{|c|}{ Interviews } & \multicolumn{2}{|c|}{ Considerations } \\
\hline & & & Yes & No & Yes & No & Partially & IIARF & Case \\
\hline 2 & Reporting relationships established & 7 & 5 & & 1 & 1 & & & 1 \\
\hline 2 & Access to information, assets and people & 4 & 1 & & & 3 & & 1 & 2 \\
\hline 3 & Funding mechanisms & 3 & & & 3 & & & & \\
\hline 3 & Management oversight of the IAF & 3 & & & 2 & & 1 & & 1 \\
\hline 4 & CAE reports to top-level authority & 3 & 2 & & 1 & & & & \\
\hline 4 & Independent oversight of the IAF & 9 & 5 & & 4 & & & & \\
\hline 5 & Independence, power and authority of the IAF & 4 & 1 & & 3 & & & & \\
\hline Total & & 33 & 14 & 0 & 14 & 4 & 1 & 1 & 4 \\
\hline
\end{tabular}

KPA, key process area; IIARF, Institute of Internal Auditors Research Foundation; IAF, internal audit function; CAE, chief audit executive.

The previous results indicate that $41.9 \%$ of the KPAs for this element were confirmed through the documentary review, and $6.5 \%$ through interviews. Aspects that could not be confirmed (51.6\%) included performing advisory services, expressing an overall opinion on governance, risk management and control and the IAF being a key agent of change. The selected case indicated that the implementation of 14 of these aspects (45.2\%) is both feasible and would add value to the effectiveness of the IAF. 
Considerations have been identified with regard to the remaining two aspects $(6.4 \%)$.

All interviewees agreed that the authority and execution of advisory services and to express an overall opinion on governance, risk management and control should be included in the internal audit charter as well as in the scope of the IAF. Although management and the audit committee do consider the IAF as value adding, they do not describe the function as a key agent of change, mainly because of the lack of objectives focussing on positive change in the organisation, assurance and advisory services for entity-level controls and new strategic initiatives in the IAF strategic documents. One of the aspects covered in the KPA 'key agent of change' is that the IAF provides audit coverage on fraud. This brought about much debate, and the ACC was of the opinion that this could be interpreted as the IAF providing assurance on this aspect, which is not acceptable. He further highlighted that the lower post level of the CAE also limited the value that could be added and the extent to which the CAE could be regarded as a key agent of change, as this could have a negative effect on the independence of the IAF.

\section{People management}

The extent to which each of the $10 \mathrm{KPAs}$ of the IA$\mathrm{CM}$ on the people management of IAFs can be effectively applied is summarised in Table 2.

The previous results indicate that $31.6 \%$ of the KPAs for this element were confirmed through the documentary review and $28.9 \%$ through interviews. Aspects that could not be confirmed (39.5\%) included recruiting skilled people, professionally qualified staff, implementing team building activities, the IAF supporting professional bodies, the IAF contributing to management development, workforce projection and the IAF leadership being involved in professional bodies. The selected case indicated that the implementation of 11 of these aspects $(29 \%)$ is both feasible and would add value to the effectiveness of the IAF. Considerations have been identified with regard to the remaining four aspects $(10.5 \%)$.

Interviewees agreed that the audit committee should be involved in the appointment of the CAE, as part of recruitment policies; staff members should be provided with the resources to become professionally qualified; team building and competency activities must be developed; professional bodies should be supported by the IAF, including leadership involvement; and a formal strategic workforce plan must be prepared. The interviews also revealed four concerns that may have a negative effect on the extent to which the corresponding KPAs can be applied. First, with regard to remuneration classification systems, in contrast with the view of the COO, the ACC and CAE indicated that the CAE was not at the correct post level that would ensure the standing and independence of the IAF. Secondly, the CAE indicated that staff retention activities should be in place, but that the lack of organisational policies prevented the IAF from implementing it. In contrast, the COO indicated that the career development of staff members should not be hindered. Thirdly, a formal rotation policy between the IAF and the rest of the organisation is not in place to enhance the KPA on the IAF's contribution to management development. The ACC and COO expressed a positive opinion, whereas the CAE raised a concern with regard to the protection of sensitive information. Fourthly, the CAE indicated that because of time constraints, involvement with professional bodies is challenging.

\section{Professional practices}

The extent to which each of the seven KPAs of the IA-CM on the professional practices of IAFs can be effectively applied is summarised in Table 3.

The previous results indicate that $36.7 \%$ of the KPAs of this element were confirmed through the documentary review and $20 \%$ through interviews. Aspects that could not be confirmed (43.3\%) relate to basing the audit plan on management priorities, implementing a professional practices framework, implementing a quality management framework, strategic internal audit planning and continuously improving in professional practices. The selected case indicated that the implementation of 13 of these aspects $(29.0 \%)$ is both feasible and would add value to the effectiveness of the IAF. No considerations have been identified for this element.

Interviewees agreed that the audit universe, engagement objectives and capability requirements should be included in the internal audit plan; a professional practices and processes framework must be developed; internal quality assessments must be conducted; strategic internal audit planning processes to identify emerging trends and risks should be formally established; and continuous improvement of professional practices did take place; however, the ACC indicated that there is still room from improvement.

\section{Performance management and accountability}

The extent to which each of the seven KPAs of the IA-CM on the performance management and 
accountability of IAFs can be effectively applied is summarised in Table 4.

The previous results indicate that only $35.3 \%$ of the KPAs for this element were confirmed through the documentary review and $29.4 \%$ through interviews. Aspects that could not be confirmed (35.3\%) related to the internal audit business plan, management reports, cost information, performance measurement integration and the public reporting of internal audit effectiveness. The selected case indicated that the implementation of 12 of these aspects $(35.3 \%)$ is both feasible and would add value to the effectiveness of the IAF. No considerations have been identified for this element.

Interviewees agreed that the business planning process of the IAF needed significant improvement; applicable management reports should be obtained timely; cost information should be used to review the effectiveness and efficiency of the IAF; although performance measures are in place, it is not optimal as the input of key stakeholders should be obtained and quality assurance reviews should be incorporated; and although other bodies do report publicly report on the effectiveness of the IAF, such reporting should be extended.

\section{Organisational relationships and culture}

The extent to which each of the five KPAs of the IA$\mathrm{CM}$ on organisational relationships and culture of IAFs can be effectively applied is summarised in Table 5.

The previous results indicate that $4.5 \%$ of the KPAs for this element were confirmed through the documentary review and $68.2 \%$ through interviews. Aspects that could not be confirmed (27.3\%) related to managing the IAF from within, coordinating with other review groups and the CAE advising management. The selected case indicated that the implementation of five of these aspects $(22.7 \%)$ is both feasible and would add value to the effectiveness of the IAF. A consideration has been identified with regard to the remaining aspect $(4.6 \%)$.

Interviewees agreed that additional skills development, the revision of the IAF structure and technology tools are required to enhance the standing of the function; coordination with other assurance providers should be enhanced; and although the CAE did contribute towards strategic issues, this contribution should be deepened. The results also revealed a consideration in implementing the KPA regarding the coordination with other review groups. The ACC indicated that the external auditors of the selected case did not generally rely on the work of internal auditing, which is supported by a study performed by Erasmus et al. (2014: 10) and which might impact negatively on assurance coordination and on the feasibility of effectively implementing this KPA.

\section{Governance structures}

The extent to which each of the five KPAs of the IA$\mathrm{CM}$ on the governance structures can be effectively applied is summarised in Table 6.

The previous results indicate that $42.4 \%$ of the KPAs for this element were confirmed through the documentary review and $42.4 \%$ through interviews. Aspects that could not be confirmed (15.2\%) related to establishing reporting relationships, access to information, assets and people and management oversight of the IAF. The selected case indicated that the implementation of four of these aspects (12.2\%) is both feasible and would add value to the effectiveness of the IAF. A consideration has been identified with regard to the remaining aspect (3.0\%).

Interviewees agreed that the internal audit charter, which formalises the reporting relationships, should be communicated throughout the organisation; and formal policies and procedures to address the right of internal auditing to access information, assets and people as well as guidelines to provide oversight of the IAF should be developed. The interviewees indicated that the IAF's authority to access information, assets and people were not documented in any other organisational policies as required by the IA-CM besides the internal audit charter. The CAE, COO and ACC indicated that owing to the fact that this authority was also documented in legislation, it was sufficient and that additional organisational policies were unnecessary. This may negatively affect the extent to which this component of the KPA regarding access to information, assets and people can be effectively applied.

\section{Ranking of the model}

Based on the research results, the extent to which the KPAs of the IA-CM have been achieved by the IAF of the selected case is summarised in Table 7 .

The previous results indicate that 16 KPAs (39.1\%) have been fully achieved, 14 KPAs (34.1\%) have been partially achieved and 11 KPAs (26.8\%) have not been achieved at all. The results also indicate that a total achievement rate of $56.1 \%$ has been recorded for the IAF of the selected case. The governance structures element of the IA-CM scored the highest achievement rate $(71.4 \%)$, and organisational relationships and culture, as well as performance 
Table 7 KPA achievement rate of the selected case's IAF

\begin{tabular}{lccccccc}
\hline $\begin{array}{l}\text { Elements } \\
\text { No. of KPAs }\end{array}$ & S \& R & PM & PP & PM \& A & OR \& C & GS & Total \\
\hline Total & 5 & 10 & 7 & 7 & 5 & 7 & 41 \\
Achieved & 2 & 3 & 2 & 3 & 2 & 4 & $16(39.1 \%)$ \\
Not achieved & 3 & 3 & 3 & 1 & 0 & 1 & $11(26.8 \%)$ \\
Partially achieved $^{\mathrm{a}}$ & 0 & 4 & 2 & 3 & 3 & 2 & $14(34.1 \%)$ \\
Achievement rate $^{2}$ & $40 \%(2 / 5)$ & $50 \%(5 / 10)$ & $42.9 \%(3 / 7)$ & $64.3 \%(4.5 / 7)$ & $70 \%(3.5 / 5)$ & $71.4 \%(5 / 7)$ & $56.1 \%(23 / 41)$
\end{tabular}

KPA, key process area; IAF, internal audit function; S \& R, Services and role; PM, People management; PP, Professional practices; PM \& A, Performance management and accountability; OR \& C, Organisational relationships and culture; GS, Governance structures.

${ }^{\mathrm{a} C}$ Calculated as achieved $=1$ and partially achieved $=0.5$.

Table 8 Ranking of the selected case's IAF

\begin{tabular}{|c|c|c|c|c|c|c|}
\hline $\begin{array}{c}\text { Capability } \\
\text { Level }\end{array}$ & $\begin{array}{l}\text { Services \& } \\
\text { Role }\end{array}$ & $\begin{array}{c}\text { People } \\
\text { Man }\end{array}$ & $\begin{array}{c}\text { Prof } \\
\text { Practices }\end{array}$ & $\begin{array}{c}\text { Perf Man } \\
\text { \& Acc }\end{array}$ & $\begin{array}{c}\text { Org } \\
R \& C\end{array}$ & $\begin{array}{c}\text { Gov } \\
\text { Structures }\end{array}$ \\
\hline 5 & $\begin{array}{c}\text { Not } \\
\text { Achieved }\end{array}$ & $\begin{array}{c}\text { Not } \\
\text { Achieved }\end{array}$ & $\begin{array}{c}\text { Not } \\
\text { Achieved }\end{array}$ & $\begin{array}{l}\text { Partially } \\
\text { Achieved }\end{array}$ & Achieved & Achieved \\
\hline 4 & $\begin{array}{c}\text { Not } \\
\text { Achieved }\end{array}$ & $\begin{array}{l}\text { Partially } \\
\text { Achieved }\end{array}$ & Achieved & $\begin{array}{c}\text { Not } \\
\text { Achieved }\end{array}$ & $\begin{array}{l}\text { Partially } \\
\text { Achieved }\end{array}$ & Achieved \\
\hline 3 & $\begin{array}{l}\text { Partially } \\
\text { Achieved }\end{array}$ & $\begin{array}{l}\text { Partially } \\
\text { Achieved }\end{array}$ & $\begin{array}{l}\text { Partially } \\
\text { Achieved }\end{array}$ & $\begin{array}{l}\text { Partially } \\
\text { Achieved }\end{array}$ & $\begin{array}{l}\text { Partially } \\
\text { Achieved }\end{array}$ & $\begin{array}{l}\text { Partially } \\
\text { Achieved }\end{array}$ \\
\hline 2 & Achieved & $\begin{array}{l}\text { Partially } \\
\text { Achieved }\end{array}$ & $\begin{array}{l}\text { Partially } \\
\text { Achieved }\end{array}$ & Achieved & $\begin{array}{l}\text { Partially } \\
\text { Achieved }\end{array}$ & $\begin{array}{c}\text { Not } \\
\text { Achieved }\end{array}$ \\
\hline 1 & & & & $\begin{array}{l}\text { Level } \\
\text { As }\end{array}$ & & \\
\hline
\end{tabular}

KPA, key process area; IAF, internal audit function.

management and accountability, scored an aboveaverage level (70\% and $64.3 \%$, respectively). The remaining elements, namely people management, professional practices and the services and role of internal auditing, scored the lowest achievement rates.

Based on the extent to which the KPAs for each level has been, the IAF of the selected case has been ranked according to the capability levels of the IA$\mathrm{CM}$. The results of this ranking have been documented in Table 8.

The previous results indicate that most of the capability levels have been partially achieved (yellow $=50 \%$ ) by the IAF of the selected case, $25 \%$ of the capability levels have not been achieved (red), while $25 \%$ of the levels have been fully achieved (green). The results also indicate that the governance structures element of the model has been achieved at the highest level, followed by the organisational relationships and culture and the performance management and accountability elements.

\section{CONCLUSION AND RECOMMENDATIONS}

The main objective of the study is to determine whether the IA-CM can be used successfully to measure internal audit capability levels, and a secondary objective is to determine whether the tool can be successfully adapted for a specific public sector organisation and/or country. This was achieved by testing the model by means of a case study in a South African public sector organisation. With regard to the first objective, the model was successfully tested 
in measuring the internal audit capability level of a South African public sector organisation. An important observation is the fact that the model does not appear to be hierarchical when applied. For example, in the professional practices element, level four appears to have been fully achieved, while levels three and two have been only partially achieved. As the model specifically states that capability levels cannot be passed over (IIARF, 2009: 54), the hierarchical building block foundation of the model should therefore be reviewed.

With regard to the second objective of the study, a total of eight potential feasibility hindrances or considerations have been identified that could negatively affect the implementation of seven of the KPAs of the IA-CM in a South African context. These hindrances indicate that it is not always possible to implement the IA-CM in its current format within a global context. Public sector internal audit environments differ from country to country, where some KPAs are more manageable than others, and can have an effect on the ability of the public sector to implement effective and capable IAFs. It is thus important that the IIARF should clearly state that the model should first be tested and adapted for a specific country, region or government before being used.

The result of the study could be enhanced by additional research, such as testing the model in other South African public sector organisations to obtain a clearer picture of the capability of IAFs in the country, whether these considerations applies to all or most IAFs, and whether the IA-CM addresses all the key problems within the profession in South Africa. This study can be echoed in other countries. A cross-country analysis can be conducted to compare the capability of IAFs within different spheres of the world.

\section{BIOGRAPHICAL NOTES}

Jacobus Janse van Rensburg is currently a senior lecturer in internal auditing at the University of Pretoria. His research interests are internal auditing in the public sector and performance auditing.

Dr Philna Coetzee is currently a consultant in internal auditing, both in academia and in practice. She has published widely in the fields of internal auditing and is currently rated by the South African National Research foundation as an accredited researcher within her discipline.

\section{REFERENCES}

Aikins SK. 2011. An Examination of Government Internal Audits' Role in Improving Financial Performance. Public Finance and Management 11(4): 306-337.
Asare T. 2009. Internal Auditing in the Public Sector: Promoting Good Governance and Performance Improvement. International Journal on Governmental Financial Management 9(1): 15-28.

Auditor General of South Africa. 2011. General report on the national audit outcomes 2009-10. Retrieved from http:/ / www.agsa.co.za. [31 August 2011].

Auditor General of South Africa. 2012. Consolidated general report on national and provincial audit outcomes of 2011-12, part 2: Audit outcomes of ministerial portfolios. Retrieved from file:///C:/Users/user/Downloads/ [18 March 2013].

Auditor General of South Africa. 2013. Consolidated general report on the national on the national and provincial audit outcomes 2012-13. Retrieved from http:// www.agsa.co.za. [3 March 2014].

Australian Securities Exchange Corporate Governance Council. 2010. Corporate governance principles and recommendations with 2010 amendments. 2nd ed. Retrieved from http://www.asx.com.au. [11 January 2014].

Becker J Niehaves B, Poeppelbuss J, Simons A 2010. Maturity models in IS research. In proceedings of the European Conference on Information Systems on 12 February 2010, paper 42. Retrieved from http://aisel.aisnet. org/ecis2010/42. [26 November 2012].

Burnaby P, Howe M, Muehlmann BW. 2011. Detecting Fraud in the Organisation: An Internal Audit Perspective. Journal of Forensic $\mathcal{E}$ Investigative Accounting 3(1): 195-233.

Businessdictionary.com. 2015. Retrieved from http:// www.businessdictionary.com/definition/ capability.html. [6 January 2015].

Chapman R. 2009. Maturity models as a vehicle for improving risk management practices. Retrieved from http:/ /blogs.exaprotect.com. [29 May 2009].

Coupland D. 1993. The Internal Auditor's Role in Public Service Orientation. Managerial Auditing Journal 8(1): 3-13.

Curristine T. 2005. Governance Performance: Lessons and Challenges. OECD Journal on Budgeting 5(1): 127-151.

De Bruin T, Freeze R, Kaulkarni U, Roseman M. 2005. Understanding the main phases of developing a maturity assessment model. In Proceedings of the Australian Conference on Information Systems (ACIS) on 30 November 2005. Retrieved from http://eprints.qut. edu.au/25152/ [29 November 2012].

Dorasamy N. 2010. The Impact of the Global Crisis on Ethical Leadership: A Case Study in the South African Public Sector. African Journal of Business Management 4(10): 2087-1096. Retrieved from http://academicjournals.org. [18 August 2011].

Erasmus L, Barac K, Coetzee P, Fourie H, Motubatse N, Plant K, Steyn B, Van Staden M. 2014. iKUTU research report: The current status of and demand for internal auditing in South African national government departments. National Treasury. Pretoria, South Africa.

Ferguson J, Ronayne P, Rybacki M. 2014. White paper. Public sector leadership challenges: Are they different and does it matter? Retrieved from www.ccl.org/leadership/ [6 January 2015].

Financial Reporting Council. 2010. The UK corporate governance code. Retrieved from http:/ /www.frc.org.uk/ documents / [13 June 2012].

Goodwin J. 2004. A comparison of internal audit in the private and public sectors. Managerial Auditing Journal 19(5): 640-650. DOI: 10.1108/02686900410537766 
Hillson DA. 1997. Towards a risk maturity model. International Journal of Project and Business Risk Management 1: $35-45$.

Institute of Directors. 2009. King report on governance for South Africa. Institute of Directors Southern Africa: Johannesburg.

Institute of Internal Auditors Research Foundation, The. 2009. Internal Audit Capability Model for the public sector. Altamonte Springs, Florida.

Institute of Internal Auditors South Africa. 2013. Public sector forum: Illuminating without fear of failure. 11-13 February. Retrieved from http://www.iiasa.org.za. [18 December 2012].

Institute of Internal Auditors, The. 2011. International Professional Practices Framework (IPPF). Altamonte Springs, Florida.

Institute of Internal Auditors, The. 2012. Supplemental Guidance: The Role of Auditing in Public Sector Governance. Altamonte Springs, Florida.

Janse van Rensburg JO, Coetzee GP. 2011. Elements of the Internal Audit Capability Model Addressed by South African Public Sector Legislation and Guidance. Southern African Journal of Accountability and Auditing Research 11: 47-62.

Jarrar Y, Schiuma G. 2007. Measuring Performance in the Public Sector: Challenges and Trends. Measuring Business Excellence 11(4): 4-8. DOI: 10.1108/13683040710 837883

Kellis DS, Ran B. 2012. Modern Leadership Principles for Public Administration: Time to Move Forward. Journal of Public Affairs 13(1): 130-141. DOI: 10.1002/pa.1453

Khoury HM. 2011. Internal audit in the public sector: The quiet revolution. Retrieved from http:/ / www.deloitte. com. [15 June 2012].

Macrae E. 2010. A Framework for Audit Evolution. Internal Auditor 67(1): 68-69.

Mafunisa MJ. 2007. Corruption and Service Delivery in the Public Service: The Case of Limpopo Province. Journal of Public Administration 42(3): 206-270.
Mihret DG, Yismaw AW. 2007. Internal Audit Effectiveness: An Ethiopian Public Sector Case Study. Managerial Auditing Journal 22(5): 470-484.

Organisation for Economic Co-operation and Development. 2004. OECD Principles of Corporate Governance. Retrieved from http://www.oecd.org. [9 April 2013].

Persse JR. 2001. Implementing the Capability Maturity Model. New York: John Wiley \& Sons.

Presidency, The. 2011. Management performance assessment tool (MPAT). Retrieved from http:/ / www.thepresidencydpme.gov.za/Pages/default.aspx. [15 February 2013].

Presidency, The. 2013. MPAT management performance assessment tool: National departments score cards. Retrieved from http:/ / www.thepresidency-dpme.gov.za/ Pages/ default.aspx. [31 January 2014].

Public Service Commission. 2010. State of the public service report. Retrieved from http://www.info.gov.za/ view. [26 October 2011].

Public Service Commission. 2011. Fact sheet on the state of the public service. Retrieved from http://www.psc. gov.za/documents [13 March 2014].

Schepers S. 2012. A Crisis of Public Affairs in Europe? Journal of Public Affairs 12(4): 333-336. DOI: 10.1002/pa.1419

Sterck M, Bouckaert G. 2006. International Audit Trends in the Public Sector. Internal Auditor 63(4): 49-53.

Subramaniam N, Ng C, Carey P. 2004. Outsourcing Internal Audit Services: An Empirical Study on Queensland Public-sector Entities. Australian Accounting Review 14(3): 86-95. DOI: $10.1111 /$ j.1835-2561.2004.tb00245.x

Van Gansberghe CN. 2005. Internal Auditing in the Public Sector. Internal Auditor 62(4): 69-73.

Van Schendelen R. 2012. New Trends of Public Affairs Management at the EU Level. Journal of Public Affairs 12(1): 39-46. DOI: 10.1002/pa.380.

World Bank, The. 2011. Accountability in public services in South Africa: Selected issues. Retrieved from http:/ / siteresources.worldbank.org [17 July 2012].

Yin RK. 2009. Case Study Research: Design and Methods (2nd edn). USA: SAGE. 